\title{
BMJ Open Are dietary vitamin D, omega-3 fatty acids and folate associated with treatment results in patients with early rheumatoid arthritis? Data from a Swedish population-based prospective study
}

\author{
Cecilia Lourdudoss, ${ }^{1}$ Alicja Wolk, ${ }^{2}$ Lena Nise, ${ }^{2}$ Lars Alfredsson, ${ }^{2}$ \\ Ronald van Vollenhoven ${ }^{1}$
}

To cite: Lourdudoss C, Wolk A, Nise L, et al. Are dietary vitamin $D$, omega- 3 fatty acids and folate associated with treatment results in patients with early rheumatoid arthritis? Data from a Swedish population-based prospective study. BMJ Open 2017;7:e016154. doi:10.1136/ bmjopen-2017-016154

- Prepublication history and additional material for this paper are available online. To view these files please visit the journal online (http://dx.doi. org/10.1136/bmjopen-2017016154)

Received 27 January 2017 Revised 28 March 2017 Accepted 10 April 2017

\section{CrossMark}

${ }^{1}$ Department of Medicine Solna, Karolinska Institutet, Stockholm, Sweden

${ }^{2}$ Department of Environmental Medicine, Karolinska Institutet, Stockholm, Sweden

Correspondence to Dr Cecilia Lourdudoss; cecilia.lourdudoss@ki.se

\section{ABSTRACT}

Background Dietary intake of vitamin D and omega-3 fatty acids (FA) may be associated with superior response to antirheumatic treatments. In addition, dietary folate intake may be associated with worse response to methotrexate (MTX). The aim of this study was to investigate the association between dietary vitamin D, omega-3 FA, folate and treatment results of disease-modifying antirheumatic drugs (DMARDs) in patients with rheumatoid arthritis (RA). Methods This prospective study was based on data from the Epidemiological Investigation of Rheumatoid Arthritis (EIRA) study, and included 727 patients with early RA from 10 hospitals in Sweden. Data on dietary vitamin D, omega-3 FA and folate intake based on food frequency questionnaires were linked with data on European League Against Rheumatism (EULAR) response after 3 months of DMARD treatment. Associations between vitamin D, omega-3 FA, folate and EULAR response were analysed with logistic regression adjusted for potential confounders.

Results The majority of patients (89.9\%) were initially treated with MTX monotherapy and more than half (56.9\%) with glucocorticoids. Vitamin D and omega-3 FA were associated with good EULAR response (OR 1.80 (95\% Cl 1.14 to 2.83 ) and $\mathrm{OR} 1.60$ (95\% $\mathrm{Cl} 1.02$ to 2.53), respectively). Folate was not significantly associated with EULAR response (OR 1.20 (95\% Cl 0.75 to 1.91)). Similar results were seen in a subgroup of patients who were initially treated with MTX monotherapy at baseline.

Conclusions Higher intake of dietary vitamin $D$ and omega-3 FA during the year preceding DMARD initiation may be associated with better treatment results in patients with early RA. Dietary folate intake was not associated with worse or better response to treatment, especially to MTX. Our results suggest that some nutrients may be associated with enhanced treatment results of DMARDs.

\section{BACKGROUND}

Treatment of rheumatoid arthritis (RA) aims at providing relief from the symptoms associated with inflammation, pain and stiffness and
Strengths and limitations of this study

- This study included a large number of participants that were representative of patients with rheumatoid arthritis in Sweden.

- The Food Frequency Questionnaire (FFQ) used in this study was highly validated.

- Serum levels of vitamin D, omega-3 fatty acids and folate were not taken into account in this study.

- Under-reporting and over-reporting of estimated dietary intake may have occurred when completing the FFQ.

- Clinical manifestations, treatment history, doses, adherence and side effects of antirheumatic treatment were not considered in this study due to lack of data.

preventing long-term disability. ${ }^{1}$ Disease-modifying antirheumatic drug (DMARD) can be effective in treating inflammation, delaying joint damage and improving outcomes on patients with RA. ${ }^{23}$ Methotrexate (MTX) is the most widely used DMARD for early RA. Low-dose glucocorticoids (GC) can be added to the treatment with MTX to achieve better outcomes. $^{4}$

The interest in dietary factors and RA has been increasing among researchers and patients with RA over the last decade. However, there is a lack of studies that have specifically investigated how certain nutrients may associate with treatment results in newly diagnosed patients with RA. Nutrients might influence the efficacy of DMARDs through influencing the gastrointestinal absorption of the drug and pharmacokinetics in other ways, or might influence the pharmacodynamic effects of the drugs. ${ }^{5}$ 
Earlier studies in RA focused on vitamin D, omega-3 fatty acids (FA) and folate. Vitamin D deficiency has been associated with an increased risk of RA. ${ }^{6}$ Serum vitamin $\mathrm{D}$ levels are decreased in patients with RA, and this was also observed in patients with RA in Sweden. ${ }^{6-10}$ Some evidence suggests that vitamin D deficiency can trigger autoimmune responses and therefore may provide an immunoregulatory effect. ${ }^{11} 12$ The active metabolite of vitamin $\mathrm{D}\left(1,25(\mathrm{OH})_{2} \mathrm{D}\right)$ inhibits the synthesis of several interleukins and tumour necrosis factor (TNF). ${ }^{13}$ It also decreases the expression of proinflammatory surface molecules. ${ }^{14}$ Vitamin D supplementation has been shown to decrease disease activity short term in patients with RA. ${ }^{15}$

Earlier data suggest that omega-3 FA are anti-inflammatory and can decrease disease activity in RA. ${ }^{16-19}$ Omega- 6 FA as well as omega-6:omega-3 FA (ratio) have been found to be proinflammatory in RA. ${ }^{20}$ Therefore, it is of importance to have a good balance between omega- 6 and omega- $3 .^{21}$ Increased dietary intake of omega-3 FA has been associated with decreased serum levels of TNF and $\mathrm{C}$ reactive protein (CRP) in $\mathrm{RA}{ }^{22}$

MTX is a folate antagonist. ${ }^{23}$ Folate stores are decreased in patients with RA treated with MTX. ${ }^{24}$ Impaired folate status is also related to MTX toxicity. Gastrointestinal intolerance is one of the side effects of MTX, and folic acid and folinic acid supplementation have been shown to reduce the mucosal and gastrointestinal side effects during low-dose MTX treatment. ${ }^{25}{ }^{26}$ Of note, excessive doses of folinic acid, but not folic acid, during MTX therapy for RA can impair efficacy. Although MTX is believed to work through folate antagonism, it has been hypothesised that the anti-inflammatory effect of this drug might be due to its stimulation of adenosine release that prevents inflammatory cells from attaching to connective tissues. ${ }^{27-29}$ Folic acid fortification in foods is mandatory in some countries (ie, USA, Canada), but not in Sweden.

We hypothesised that higher dietary intake of vitamin $\mathrm{D}$ and omega-3 FA may be associated with superior responses to antirheumatic treatments, whereas higher dietary folate intake might be associated with worse response to MTX. The aim of this study was to investigate the association between dietary intake of vitamin $\mathrm{D}$, omega-3 FA, folate and treatment results of DMARDs in patients with early RA.

\section{MATERIAL AND METHODS}

\section{Study participants}

This study included initially 1296 newly diagnosed patients with RA (disease duration $\leq 12$ months) from a population-based prospective case-control study called Epidemiological Investigation of Rheumatoid Arthritis (EIRA). EIRA was initiated in May 1996 and the study design has previously been described. ${ }^{30}$ Participants of EIRA were asked to complete a Food Frequency Questionnaire (FFQ) at inclusion/baseline. ${ }^{31}{ }^{32}$ EIRA has been linked to the Swedish Rheumatology Quality register to
EIRA inclusion from October 2005 to March 2012

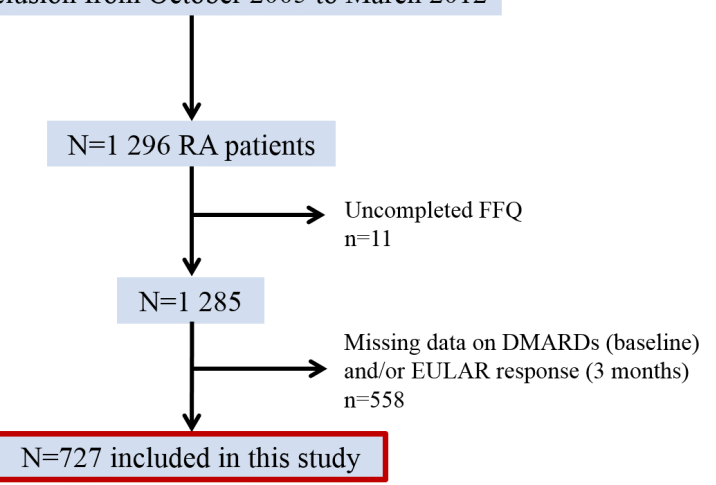

Figure 1 Overview of patient exclusions. DMARDs, diseasemodifying antirheumatic drugs; EIRA, Epidemiological Investigation of Rheumatoid Arthritis; EULAR, European League Against Rheumatism; FFQ, Food Frequency Questionnaire; RA, rheumatoid arthritis.

provide clinical data. The study period for this report was from October 2005 to March 2012. Patients who did not fully complete the FFQ and/or had missing data on DMARD use at baseline as well as treatment results (European League Against Rheumatism (EULAR) response) after 3 months were excluded. After exclusions, 727 patients remained for analyses (figure 1). This study was approved by the Regional Ethical Review Board at Karolinska Institutet, Stockholm, Sweden.

\section{Dietary assessment}

EIRA participants were asked to complete a FFQ at baseline. This self-administered, semiquantitative FFQ included questions regarding frequency intake of 123 food items and beverages during the previous year before baseline. Prespecified food frequency intake ranged over eight categories from never to $\geq 3$ times per day. For frequently consumed foods, open questions were used and the participants could fill in number of slices, cups, glasses, etc. Dietary nutrient intake of vitamin D ( $\mu \mathrm{g} /$ day), omega-3 FA (g/day) and folate ( $\mu \mathrm{g} /$ day) were calculated by multiplying the average frequency of consumption of each food item by the nutrient content, the nutrient content values were obtained from the Swedish Food Administration Database. ${ }^{33}$ Total omega-3 FA intake was calculated based on the most common FA of omega-3 ( (alpha-linolenic acid, C18:3/10)+(eicosapentaenoic acid, C20:5) $+($ docosapentaenoic acid, C22:5) $+($ docosahexaenoic acid, C22:6)). ${ }^{34}{ }^{35}$ All dietary nutrients were energy adjusted to the mean energy intake during the precious year from baseline in the study population using the residual method. ${ }^{36}$ This dietary assessment method and the validation of this FFQ have been described previously. ${ }^{31}{ }^{32}$ The FFQ included also questions regarding dietary supplement use of vitamin D, omega-3 FA/fish oil as well as folic acid (yes or no) during the previous year before baseline.

The estimated FFQ-based intakes of vitamin D-rich foods were validated in comparison to $4 \times 1$ week weighed 
dietary records among 129 persons. Pearson's correlations $(r)$ between reported dietary vitamin $\mathrm{D}$ intake and vitamin D-fortified reduced-fat dairy products, vitamin D-fortified margarines and fatty fish were 0.60-0.70, 0.300.70 and 0.50 , respectively (Wolk, A et al, unpublished observations, 1992). Furthermore, serum concentrations of $25(\mathrm{OH}) \mathrm{D}$ among 116 persons have been significantly correlated with the FFQ-based vitamin D intake of fatty fish $(\mathrm{r}=0.21, \mathrm{p}=0.02)$ and vitamin $\mathrm{D}$-fortified reduced-fat dairy products $(\mathrm{r}=0.20, \mathrm{p}=0.04) .{ }^{37}$ Estimate of FFQ-based omega-3 FA intake has been validated in comparison to adipose tissue composition in 239 persons and in comparison to $4 \times 1$ week weighed dietary records in 184 persons. Pearson's correlation between the estimated intake of omega-3 FA and adipose tissue was $0.41^{38}$ and 0.40 with dietary records. ${ }^{39}$ Pearson's correlation was 0.50 between the estimated intake of folate and $4 \times 1$ week weighed dietary records of folate intake $(n=129) .{ }^{40}$ The validity of a FFQ can differ between different populations.

\section{Additional assessments}

In addition to the FFQ the EIRA participants were asked to report their age, weight, height, smoking habits, education and physical activity (PA) level. The EIRA questionnaire included questions regarding smoking status (never, former or current smoker) as well as smoking duration and intensity (pack-year). Pack-years were categorised into 0-9, 10-19 and 20+ pack-years; one pack-year was equal to 20 smoked cigarettes per day during 1 year. $^{41}$ Education level was categorised into high school and university degree. The participants reported the amount of PA performed during the previous year before inclusion in the EIRA study. PA was categorised into four groups: sedentary PA, moderate occasional PA, moderate regular PA and regular exercise.

\section{Treatment result assessment}

Treatment results were assessed using EULAR response criteria, which is validated tool for assessing treatment efficacy in RA. ${ }^{42-44}$ It includes non-response, moderate response and good response to treatment. EULAR response was determined based on changes in 28-joint Disease Activity Score (DAS28) from baseline/ treatment initiation up to 3 months as well as the endpoint DAS28 at 3 months. EULAR response was studied primarily in all patients with any DMARD at baseline, and then specifically in all patients with MTX monotherapy at baseline. In this study, non-EULAR response and moderate EULAR response were merged into one category to increase stratified power.

\section{Statistical analysis}

Statistical analysis was performed with IBM SPSS Statistics V.23. Baseline characteristics were compared between non-responders/moderate responders and good responders after 3 months with Mann-Whitney U test or Kruskal-Wallis test for continuous variables (mean and SD) as well as Pearson's $\chi^{2}$ test for proportions (\%).
Further analyses included comparisons of dietary intake of vitamin D, omega-3 FA and folate between different subgroups of patients based on age, sex, smoking, supplement use, body mass index (BMI), education, PA, geographical locations and season (spring/summer vs fall/winter) at EIRA inclusion, with Mann-Whitney U test and Kruskal-Wallis test.

Associations between dietary intake of vitamin D, omega-3 FA, folate and EULAR response, respectively, were analysed with logistic regression. All multivariate analyses were adjusted for potential confounders such as age, sex, smoking, total energy intake, supplement use (vitamin D, omega-3 FA/fish oil and folic acid), BMI (weight $(\mathrm{kg}) /\left(\right.$ height $\left(\mathrm{m}^{2}\right)$ ) education, PA, DAS28 at baseline and antirheumatic treatment at baseline. Dietary intakes of vitamin D, omega-3 FA and folate were divided into quartiles based on intake of all the EIRA participants including the controls. The first quartile was the referent group. Age was categorised into 11 age groups of 5-year range each, total energy intake into quartiles, supplement use into yes and no, education into high school degree and university degree and PA into sedentary to occasional moderate PA and moderate regular PA to regular exercise. BMI and DAS28 at baseline were used as continuous variables. Use of antirheumatic treatment was categorised into yes and no for each treatment. Smoking adjustment was based on pack-years. The analyses were primarily including the total study sample regardless of treatment $(n=727)$. The same analyses were also performed separately on patients with only MTX monotherapy $(n=653)$. Further sensitivity analyses were performed where EULAR response of three separate groups (non, moderate, good) was used as the outcome in an ordinal regression. In addition, association between omega-3/fish oil supplementation and EULAR response were analysed.

\section{RESULTS}

\section{Patient characteristics}

This study included 727 patients with RA. Baseline characteristics for the total study sample are presented in table 1. The proportion of current smokers was 31.9\% and obtained university degree $25.2 \%$ (no one had an education level below high school degree). The proportions of patients who had performed moderate regular PA to regular exercise was $30.7 \%$.

After 3 months, 140 patients $(19.3 \%)$ had non-EULAR response, 259 patients $(35.6 \%)$ had moderate EULAR response and 328 patients $(45.1 \%)$ had good EULAR response. Good responders, in comparison to non-responders to moderate responders, had significantly lower BMI $\left(25.1 \pm 4.4\right.$ vs $\left.26.2 \pm 4.8 \mathrm{~kg} / \mathrm{m}^{2}, \mathrm{p}=0.005\right)$ and lower baseline tender joint count (TJC; $7.5 \pm 6.3$ vs $8.8 \pm 6.3, \mathrm{p}=0.019)$. The remaining baseline characteristics as well as smoking status did not differ significantly between non-responders to moderate and good responders. 
Table 1 Clinical baseline characteristics

$\mathrm{n}=727$

\begin{tabular}{ll}
\hline Female (\%) & 72.6 \\
\hline Age (years), mean \pm SD & $52.5 \pm 13.1$ \\
\hline BMI (kg/m²), mean \pm SD & $25.7 \pm 4.6$ \\
\hline Symptom duration (days), mean \pm SD & $302.3 \pm 419.1$ \\
\hline Rheumatoid factor, positive (\%) & 51.4 \\
\hline ACPA positive (\%) & 66.2 \\
\hline DAS28, mean $\pm S D$ & $5.2 \pm 1.3$ \\
HAQ, mean \pm SD & $1.0 \pm 0.6$ \\
\hline CRP (mg/L), mean $\pm S D$ & $22.6 \pm 29.8$ \\
\hline Pain (VAS 0-100 mm), mean $\pm S D$ & $53.5 \pm 24.7$ \\
\hline Patients' global assessment (VAS & $51.0 \pm 24.4$ \\
O-100 mm), mean $\pm S D$ & \\
\hline Physicians' global assessment (five-point & $2.2 \pm 0.7$ \\
scale), mean $\pm S D$ & \\
\hline SJC, mean $\pm S D$ & $9.2 \pm 5.4$ \\
\hline TJC, mean $\pm S D$ & $8.2 \pm 5.9$ \\
\hline
\end{tabular}

ACPA, anticitrullinated protein antibody; BMI, body mass index; CRP, C reactive protein; DAS28, 28-joint Disease Activity Score; HAQ, Health Assessment Questionnaire; SJC, swollen joint count; TJC, tender joint count; VAS, Visual Analogue Scale.

\section{Treatment use}

The majority of the patients $(89.9 \%)$ were initially treated with MTX monotherapy, $5.9 \%$ with sulfasalazine (SSZ) and 2.3\% with triple therapy (MTX, SSZ, hydroxychloroquine (HCQ)). More than half of the patients $(56.9 \%)$ combined their DMARD treatment with GC. Similar pattern of treatment use was seen at the 3-month follow-up (table 2). The comparison of treatment patterns between the different EULAR response groups after 3 months showed that triple therapy at baseline was more common in good responders than non-responders to moderate responders ( $3.7 \%$ vs $1.7 \%, \mathrm{p}=0.046$ ), and combined therapy of MTX and SSZ at 3 months was more common in non-responders to moderate responders ( $4.3 \%$ vs $1.0 \%, \mathrm{p}=0.009)$.

\section{Nutrient intake and treatment results}

The mean (SD) of the energy intake was 1939 (693) kcal, the median (IQR) was 1838 (1480-2266) kcal. The mean intake of vitamin D, omega-3 FA and folate as well as supplement use in the whole study sample and in different EULAR response groups are presented in table 3. Mean omega-3 FA intake at baseline was significantly higher in good responders. No difference between responders and non-responders was seen for vitamin $\mathrm{D}$ and folate intake. Dietary supplement use did not differ significantly across EULAR response groups. The intakes of both vitamin D and omega-3 were below the Recommended Daily Intake (RDI) and the intake of folate was borderline to the RDI according to Nordic Nutrition Recommendations 2012. ${ }^{45}$

Further, vitamin D intake was found to be significantly higher in males and patients with higher BMI $(>25 \mathrm{~kg}$ / $\mathrm{m}^{2}$ ). Omega-3 and folate intakes were higher in patients with a university degree and higher PA but lower in smokers. In addition, nutrient intakes between the different study centres did not significantly differ due to their geographical locations or the season at EIRA inclusion (data not shown).

Dietary vitamin D and omega-3 FA intake were associated with good EULAR response, after adjustment for age, sex, smoking, total energy intake, supplementation, BMI, education, PA, DAS28 at baseline and use of DMARDs and GC at baseline. However, dietary folate intake did not significantly associate with EULAR response (table 4). Additional analysis showed that omega-6:3 FA did not associate with EULAR response (OR 0.73 (95\% CI 0.47 to

Table 2 Treatment use at baseline and at 3 months follow-up

\begin{tabular}{lcccc}
\hline & Baseline & \multicolumn{3}{c}{ 3 months } \\
\hline Treatment & $\mathbf{n}(\%)$ & GC use $\mathbf{n}(\%)$ & $\mathbf{n}(\%)$ & GC use $\mathbf{n}(\%)$ \\
\hline MTX $^{*}$ & $653(89.9)$ & $373(90.1)$ & $579(79.6)$ & $351(85.8)$ \\
SSZ & $43(5.9)$ & $18(4.3)$ & $31(4.3)$ & $18(4.4)$ \\
MTX+SSZ+HCQ & $17(2.3)$ & $15(3.6)$ & $31(4.3)$ & $18(4.4)$ \\
HCQ & $8(1.1)$ & $3(0.7)$ & $9(1.2)$ & $5(1.2)$ \\
LFM & $2(0.3)$ & $1(0.2)$ & $0(0)$ & $0(0)$ \\
AZA & $1(0.1)$ & $1(0.2)$ & $0(0)$ & $0(0)$ \\
MTX+SSZ & $1(0.1)$ & $1(0.2)$ & $19(2.6)$ & $9(2.2)$ \\
HCQ+SSZ & $1(0.1)$ & $0(0)$ & $2(0.3)$ & $2(0.5)$ \\
HCQ+AZA & $1(0.1)$ & $1(0.2)$ & $1(0.1)$ & $1(0.2)$ \\
GC & $414(56.9)$ & - & $432(59.4)$ & - \\
Missing data & $0(0)$ & - & $46(6.3)$ & - \\
\hline
\end{tabular}

${ }^{*}$ Oral treatment.

AZA, azathioprine; GC, glucocorticoids; HCQ, hydroxychloroquine; LFM, leflunomide; MTX, methotrexate; SSZ, sulfasalazine. 
Table 3 The mean intake of vitamin D, omega-3 FA, folate and dietary supplement use during the previous year from study inclusion in the whole study sample as well as in different EULAR response groups

\begin{tabular}{|c|c|c|c|c|}
\hline \multirow[b]{3}{*}{ Nutrient intake } & \multirow{3}{*}{$\begin{array}{l}\text { Total study sample } \\
(\mathrm{n}=727)\end{array}$} & \multicolumn{3}{|c|}{ EULAR response at 3 months } \\
\hline & & Non-/moderate & Good & \\
\hline & & $(n=399)$ & $(n=328)$ & p Value* \\
\hline \multicolumn{5}{|l|}{ Vitamin D } \\
\hline Dietary intake, $\mu \mathrm{g} /$ day, $\operatorname{mean}_{ \pm} \mathrm{SD}$ & $5.86 \pm 2.30$ (RDI 10-20) & $5.68 \pm 2.15$ & $6.07 \pm 2.45$ & 0.062 \\
\hline Supplementation, n (\%) & $57(7.8)$ & $29(7.3)$ & $28(8.5)$ & 0.580 \\
\hline \multicolumn{5}{|l|}{ Omega-3 FA } \\
\hline Dietary intake, g/day, mean \pm SD & $0.68 \pm 0.35(\mathrm{RDI} \geq 2.15)^{\dagger}$ & $0.65 \pm 0.30$ & $0.71 \pm 0.39$ & 0.040 \\
\hline Supplementation, n (\%) & $142(19.5)$ & 85 (21.3) & $57(17.4)$ & 0.222 \\
\hline \multicolumn{5}{|l|}{ Folate } \\
\hline Dietary intake, $\mu \mathrm{g} /$ day, mean $\mathrm{SD}$ & $308.39 \pm 107.09$ (RDI 300-400) & $308.28 \pm 115.00$ & $308.52 \pm 101.57$ & 0.417 \\
\hline Supplementation, n (\%) $)^{\ddagger}$ & $113(15.5)$ & $67(16.8)$ & $46(14.0)$ & 0.355 \\
\hline
\end{tabular}

RDI according to Nordic Nutrition Recommendations $2012 .{ }^{45}$ The recommendations are age and gender specific. Women and men $\geq 75$ years are recommended a daily intake of $20 \mu \mathrm{g}$ of vitamin D. Both women and men are recommended a daily intake of omega-3 fatty acids that equals 1 energy per cent $(E \%)$ or more of the total daily energy intake. Women in fertile age are recommended a daily intake of $400 \mu g$ of folate, other women as well as men are recommended $300 \mu \mathrm{g}$.

*Mean intakes and proportions of supplementation between non-response/moderate response and good EULAR response were compared with Mann-Whitney $U$ test and Pearson's $\chi^{2}$ test, respectively.

†RDI for this particular study sample equals $\geq 1 \mathrm{E} \%$ of the total energy intake of the study sample (1939 kcal).

‡Folate supplementation use before treatment start. All patients who eventually started MTX treatment were also receiving folate supplements.

BMI, body mass index; EIRA, Epidemiological Investigation of Rheumatoid Arthritis; EULAR, European League Against Rheumatism; FA, fatty acid; MTX, methotrexate; PA, physical activity; RDI, recommended daily intake.

1.14)). Further adjustments for season of EIRA inclusion did not change the ORs markedly (results not shown).

Similar results were seen in subgroup of the 653 patients who were initially treated with MTX monotherapy at baseline (OR 1.63 (95\% CI 1.03 to 2.57) for vitamin D, OR 1.65 (95\% CI 1.05 to 2.60) for omega-3 FA and OR 1.20 (95\% CI 0.76 to 1.89 ) for folate, after adjustment for age and gender).

Further sensitivity analyses when using EULAR response of three separate groups as the outcome (non, moderate, good) in an ordinal regression did not show stronger associations as in logistic regression, after adjusting for age, sex, smoking, total energy intake, supplementation, BMI, education, PA, DAS28 at baseline and use of DMARDs and GC at baseline (OR 1.14 (95\% CI 0.99 to 1.30) for vitamin D, OR 1.30 (95\% CI 1.03 to 1.34) for omega-3 FA and OR 1.06 (95\% 0.93-1.22) for folate).

Dietary supplementation alone did not associate with EULAR response (OR 1.27 (95\% CI 0.73 to 2.20) for vitamin D, OR 81 (95\% CI 0.56 to 1.87) for omega-3 FA and OR 0.82 (95\% CI 0.54 to 1.23) for folate, after adjustment for age and gender). In addition, patients who took supplements did not have significantly higher dietary intake of the three nutrients, compared with the patients without supplementation.

\section{DISCUSSION}

This study investigated the dietary intake of vitamin D, omega-3 FA and folate prior to DMARD initiation, and their associations with treatment results in patients with early RA. Omega-3 FA intake was significantly higher in patients with good response compared with patients with non- to moderate response. Higher vitamin D and omega-3 FA intakes were associated with good EULAR response. However, no association was found between folate intake and EULAR response. Similar results were observed in a subgroup of patients who were treated with MTX monotherapy at baseline. Dietary supplementation of vitamin D, omega-3 FA and folate alone were not associated with EULAR response.

\section{Vitamin D, omega-3 FA, folate and EULAR response}

We found that higher intake of dietary vitamin $\mathrm{D}$ was associated with good EULAR response. A study, performed in Philadelphia, USA, showed no association between vitamin D concentration levels and clinical response to therapy using American College of Rheumatology response in treatment-naive $\mathrm{RA}$ patients, ${ }^{46}$ however, in contrast to our study, vitamin D intake in particular was not studied. Only $15 \%-20 \%$ of the vitamin D in blood originates directly from the diet, the remainder is produced during sunlight exposure. ${ }^{47}$ Vitamin D deficiency measured in blood is common in patients with RA and has been associated with disease activity and inflammatory markers. ${ }^{1248}$ Vitamin D deficiency in patients with RA in Sweden might be caused or aggravated by limited sun exposure during the winter months as there is only enough UV radiation from the sun to produce vitamin D during 6 months each year. However, our results showed that vitamin D intake did not significantly differ between 
Table 4 Association between dietary intake of vitamin D, omega-3 FA, folate and EULAR response after 3 months

\begin{tabular}{|c|c|c|c|}
\hline Nutrient intake & $\mathbf{n}$ & $\begin{array}{l}\text { OR (95\% Cl) } \\
\text { Age and sex adjustment }\end{array}$ & $\begin{array}{l}\text { OR }(95 \% \mathrm{Cl}) \\
\text { Multivariable adjustment }\end{array}$ \\
\hline Vitamin D & 727 & & \\
\hline First quartile: $\leq 4.25 \mu \mathrm{g} /$ day & 182 & 1.00 & 1.00 \\
\hline Second quartile: $4.26-5.42 \mu \mathrm{g} /$ day & 170 & 1.07 (0.70 to 1.64$)$ & 0.94 (0.59 to 1.50$)$ \\
\hline Third quartile: $5.43-6.96 \mu \mathrm{g} /$ day & 184 & 1.15 (0.75 to 1.77$)$ & $1.11(0.70$ to 1.76$)$ \\
\hline Fourth quartile: $>6.97 \mu \mathrm{g} /$ day & 191 & 1.75 (1.13 to 2.71$)$ & 1.61 (1.01 to 2.57$)$ \\
\hline $\mathrm{p}$ Value, quartile 4 vs 1 & & 0.012 & 0.048 \\
\hline Omega-3 FA & 727 & & \\
\hline First quartile: $\leq 0.45 \mathrm{~g} /$ day & 180 & 1.00 & 1.00 \\
\hline Second quartile: $0.46-0.62 \mathrm{~g} / \mathrm{day}$ & 192 & 1.25 (0.82 to 1.89$)$ & 1.28 (0.82 to 2.00$)$ \\
\hline Third quartile: $0.63-0.83 \mathrm{~g} /$ day & 183 & 1.35 (0.89 to 2.07$)$ & 1.35 (0.85 to 2.13 ) \\
\hline Fourth quartile: $>0.84 \mathrm{~g} /$ day & 172 & 1.64 (1.07 to 2.53$)$ & 1.68 (1.05 to 2.68$)$ \\
\hline p Value, quartile 4 vs 1 & & 0.024 & 0.030 \\
\hline Folate & 727 & & \\
\hline First quartile: $\leq 244.88 \mu \mathrm{g} /$ day & 201 & 1.00 & 1.00 \\
\hline Second quartile: $244.89-296.86 \mu \mathrm{g} /$ day & 182 & 1.32 (0.88 to 1.99$)$ & $1.40(0.90$ to 2.16$)$ \\
\hline Third quartile: $296.87-365.70 \mu \mathrm{g} /$ day & 193 & 1.59 (1.07 to 2.38$)$ & 1.66 (1.07 to 2.58$)$ \\
\hline Fourth quartile: $>365.71 \mu \mathrm{g} /$ day & 151 & $1.14(0.74$ to 1.75$)$ & 1.11 (0.69 to 1.79$)$ \\
\hline $\mathrm{p}$ value, quartile 4 vs 1 & & 0.557 & 0.672 \\
\hline
\end{tabular}

Multivariable adjustment for age (11 5-year age groups), sex, smoking pack-years, total energy intake (tertiles), supplementation (vitamin D, omega-3 FA/fish oil and folic acid), BMI (continuous), education level (high school and university) and PA (sedentary PA, moderate occasional PA, moderate regular PA and regular exercise), DAS28 at baseline (continuous) and use of DMARDs and GC baseline (yes or no). $p$ Value: comparison between fourth and first quartiles.

BMI, body mass index; DAS28, 28-joint Disease Activity Score; DMARDs, disease-modifying antirheumatic drugs; EULAR, European League Against Rheumatism; FA, fatty acid; GC, glucocorticoids; PA, physical activity.

study centres by geographical locations or by the season of inclusion into EIRA. Therefore, increased vitamin D intake through either diet or supplementation might be of importance. Our results suggest that increased dietary intake of vitamin D before and/or during DMARD start may be associated with improved treatment outcome in patients with RA. This finding requires confirmation.

Dietary omega-3 FA intake was associated with good EULAR response. Evidence suggests that long-chain omega-3 FA have anti-inflammatory properties and are beneficial in the treatment of autoimmune and inflammatory conditions. ${ }^{49}{ }^{50}$ Combination of MTX and omega-3 has shown a significant reduction in liver enzyme activities. ${ }^{51}$ In line with our results, a recent study has suggested that biomarkers of omega-3 FA may predict clinical outcomes relevant to standard drug treatment of patients with RA. ${ }^{52}$ In addition to the anti-inflammatory effect of the DMARDs, omega-3 FA may have a supplementary role in reducing inflammation and/or achieving better treatment outcome in early RA.

MTX was used by the majority of the patients. We did not find that higher dietary folate intake before starting with MTX and/or other DMARDs was associated with worse treatment response. Folate fortification in food items such as flour, rice, pasta and other grain products has been common in the last two decades to primarily prevent neural tube defect in unborn children, ${ }^{53}{ }^{54}$ but not in Sweden. Folic supplementation in patients with RA using MTX has shown to prevent side effects of the drug. ${ }^{25}$ Dietary folate intake during MTX treatment might have adverse effects on MTX efficacy. Folic acid fortification in foods has been associated with requirement for higher MTX dose in a small study of patients with RA. ${ }^{55}$ However, in Sweden, there is no obligatory fortification of food. Results from our study, performed in a country where there is no obligatory fortification, suggest that dietary folate intake before starting with MTX and/or other DMARDs did not associate with inferior EULAR response.

This study did not show any association between dietary supplementation and EULAR response, although, several studies have reported beneficial effect of supplementation of vitamin D and omega-3 FA/fish oil) in particular. ${ }^{49} 505657$ This could partly be explained due to higher bioavailability of the nutrients in foods rather than supplements.

This study is to our knowledge the first to investigate the dietary intake of vitamin D, omega-3 FA and folate prior to DMARD initiation, and their associations with treatment results in patients with early RA. Our study included a large number of participants that were representative of patients with RA in Sweden. The FFQ used in 
this study was highly validated. The results of our study apply to Swedish patients with newly diagnosed RA. It is very likely that they also apply to patients with newly diagnosed RA in other European countries and North America. It is also likely that they apply to patients with established RA as well as some other autoimmune inflammatory conditions.

Serum levels of vitamin D, omega-3 FA and folate were not taken into account in this study. Dietary data from FFQ were based on estimated dietary consumption as assessed close to the start of treatment. Information on food preparation and its influence on nutrient content was not available. Under-reporting and over-reporting may have occurred when completing the FFQ. This may have introduced non-differential misclassification of exposure, which would result that the ORs for the comparisons between the extreme groups (fourth versus first quartile) were biased towards the null value. Dietary patterns were assumed to be unchanged during the first 3 months from baseline. Clinical RA manifestations, treatment history, doses, adherence and side effects of DMARDs from treatment initiation were not considered in this study due to lack of data. The majority of the patients were treated with MTX, the number of patient with other DMARDs were limited to perform sensitivity analysis in subgroups of other DMARDs.

\section{Conclusions}

Higher intake of dietary vitamin D and omega-3 FA during the year preceding DMARD initiation may be associated with better treatment results in early patients with RA. Higher dietary folate intake was not associated with worse responses to MTX. These results, if confirmed, suggest that dietary interventions may be of interest in the management of RA, not only for reasons of optimising general health but also for achieving optimal results with anti-rheumatic medications.

Contributors LA was instrumental in establishing the Epidemiological Investigation of RheumatoidArthritis (EIRA) study. LN provided data from the EIRA master file. RVV played a major role in the study design and drafting the manuscript together with CL. CL performed all the statistical analyses. RVV, AW and LA contributed to the interpretation of the results from a clinical, nutritional and epidemiological aspect, respectively. All authors approved the final manuscript.

Funding This research received no specific grant from any funding agency in the public, commercial or not-for-profit sectors.

Competing interests None declared.

Patient consent Obtained from patients.

Ethics approval Regional Ethical Review Board at Karolinska Institutet.

Provenance and peer review Not commissioned; externally peer reviewed.

Data sharing statement № additional data are available.

Open Access This is an Open Access article distributed in accordance with the Creative Commons Attribution Non Commercial (CC BY-NC 4.0) license, which permits others to distribute, remix, adapt, build upon this work non-commercially, and license their derivative works on different terms, provided the original work is properly cited and the use is non-commercial. See: http://creativecommons.org/ licenses/by-nc/4.0/

(C) Article author(s) (or their employer(s) unless otherwise stated in the text of the article) 2017. All rights reserved. No commercial use is permitted unless otherwise expressly granted.

\section{REFERENCES}

1. Arnett FC, Edworthy SM, Bloch DA, et al. The American Rheumatism Association 1987 revised criteria for the classification of Rheumatoid arthritis. Arthritis Rheum 1988;31:315-24.

2. Smolen JS, Landewé R, Breedveld FC, et al. EULAR recommendations for the management of rheumatoid arthritis with synthetic and biological disease-modifying antirheumatic drugs: 2013 update. Ann Rheum Dis 2014;73:492-509.

3. Cohen S, Cannon GW, Schiff M, et al. Two-year, blinded, randomized, controlled trial of treatment of active rheumatoid arthritis with leflunomide compared with methotrexate. utilization of Leflunomide in the treatment of rheumatoid Arthritis Trial Investigator Group. Arthritis Rheum 2001;44:1984-92.

4. Svensson B, Hafström I. [Evidence for low-dosage prednisolone in early rheumatoid arthritis. prevents destruction of the joints and relieves symptoms]. Lakartidningen 2006;103:3704-9.

5. Zhang L, Brett CM, Giacomini KM. Role of organic cation transporters in drug absorption and elimination. Annu Rev Pharmacol Toxicol 1998;38:431-60.

6. Song GG, Bae SC, Lee YH. Association between vitamin D intake and the risk of rheumatoid arthritis: a meta-analysis. Clin Rheumatol 2012;31:1733-9.

7. Costenbader KH, Feskanich D, Holmes M, et al. Vitamin D intake and risks of systemic lupus erythematosus and rheumatoid arthritis in women. Ann Rheum Dis 2008;67:530-5.

8. Merlino LA, Curtis J, Mikuls TR, et al. Vitamin D intake is inversely associated with rheumatoid arthritis: results from the lowa Women's Health Study. Arthritis Rheum 2004;50:72-7.

9. Sabbagh Z, Markland J, Vatanparast H. Vitamin D status is associated with disease activity among rheumatology outpatients. Nutrients 2013;5:2268-75.

10. Kerr GS, Sabahi I, Richards JS, et al. Prevalence of vitamin D insufficiency/deficiency in rheumatoid arthritis and associations with disease severity and activity. J Rheumatol 2011;38:53-9.

11. Cutolo M, Pizzorni C, Sulli A. Vitamin D endocrine system involvement in autoimmune rheumatic diseases. Autoimmun Rev 2011;11:84-7.

12. Cutolo M, Straub RH. Insights into endocrine-immunological disturbances in autoimmunity and their impact on treatment. Arthritis Res Ther 2009;11:218.

13. Luo J, Wen H, Guo H, et al. 1,25-dihydroxyvitamin $\mathrm{D} 3$ inhibits the RANKL pathway and impacts on the production of pathwayassociated cytokines in early rheumatoid arthritis. Biomed Res Int 2013;2013:1-9.

14. Almerighi C, Sinistro A, Cavazza A, et al. 1 Alpha, 25-dihydroxyvitamin D3 inhibits CD40L-induced pro-inflammatory and immunomodulatory activity in human monocytes. Cytokine 2009;45:190-7.

15. Chandrashekara S, Patted A. Role of vitamin D supplementation in improving disease activity in rheumatoid arthritis: an exploratory study. Int J Rheum Dis 2015:n/a.

16. Wall R, Ross RP, Fitzgerald GF, et al. Fatty acids from fish: the antiinflammatory potential of long-chain omega-3 fatty acids. Nutr Rev 2010;68:280-9.

17. Ariza-Ariza R, Mestanza-Peralta M, Cardiel MH. Omega-3 fatty acids in rheumatoid arthritis: an overview. Semin Arthritis Rheum 1998;27:366-70.

18. Adam $\mathrm{O}$, Beringer $\mathrm{C}$, Kless $\mathrm{T}$, et al. Anti-inflammatory effects of a low arachidonic acid diet and fish oil in patients with rheumatoid arthritis. Rheumatol Int 2003;23:27-36.

19. Sperling RI. The effects of dietary $n-3$ polyunsaturated fatty acids on neutrophils. Proc Nutr Soc 1998;57:527-34.

20. James MJ, Cleland LG. Dietary n-3 fatty acids and therapy for rheumatoid arthritis. Semin Arthritis Rheum 1997;27:85-97.

21. Simopoulos AP. The importance of the ratio of omega-6/omega-3 essential fatty acids. Biomed Pharmacother 2002;56:365-79.

22. Sundrarjun T, Komindr S, Archararit N, et al. Effects of $n-3$ fatty acids on serum interleukin-6, tumour necrosis factor-alpha and soluble tumour necrosis factor receptor p55 in active rheumatoid arthritis. $J$ Int Med Res 2004;32:443-54.

23. Dijkmans BA. Folate supplementation and methotrexate. $\mathrm{Br} \mathrm{J}$ Rheumatol 1995;34:1172-4.

24. Morgan SL, Baggott JE, Altz-Smith M. Folate status of rheumatoid arthritis patients receiving long-term, low-dose methotrexate therapy. Arthritis Rheum 1987;30:1348-56.

25. Morgan SL, Baggott JE, Vaughn WH, et al. Supplementation with folic acid during methotrexate therapy for rheumatoid arthritis. A double-blind, placebo-controlled trial. Ann Intern Med 1994;121:833-41.

26. Ortiz Z, Shea B, Suarez Almazor M, et al. Folic acid and folinic acid for reducing side effects in patients receiving methotrexate for rheumatoid arthritis. Cochrane Database Syst Rev 2000:CD000951. 
27. Cronstein BN, Eberle MA, Gruber HE, et al. Methotrexate inhibits neutrophil function by stimulating adenosine release from connective tissue cells. Proc Natl Acad Sci U S A 1991;88:2441-5.

28. Cronstein BN, Naime D, Ostad E. The antiinflammatory mechanism of methotrexate. increased adenosine release at inflamed sites diminishes leukocyte accumulation in an in vivo model of inflammation. J Clin Invest 1993;92:2675-82.

29. Cronstein BN. Low-dose methotrexate: a mainstay in the treatment of rheumatoid arthritis. Pharmacol Rev 2005;57:163-72.

30. Stolt $P$, Bengtsson C, Nordmark B, et al. Quantification of the influence of cigarette smoking on rheumatoid arthritis: results from a population based case-control study, using incident cases. Ann Rheum Dis 2003:62:835-41.

31. Messerer M, Johansson SE, Wolk A. The validity of questionnairebased micronutrient intake estimates is increased by including dietary supplement use in swedish men. J Nutr 2004;134:1800-5

32. Larsson SC, Håkansson N, Giovannucci E, et al. Folate intake and pancreatic Cancer incidence: a prospective study of Swedish women and men. J Natl Cancer Inst 2006;98:407-13.

33. Bergström LKE, Hagman U, Eriksson $\mathrm{HB}$, et al. Livsmedelsdatasystemet KOST - livsmedelsverkets system för information om näringsvärden i livsmedel. Vår Föda 1991;43:439-47.

34. Gerster H. Can adults adequately convert alpha-linolenic acid (18:3n$3)$ to eicosapentaenoic acid (20:5n-3) and docosahexaenoic acid (22:6n-3)? Int J Vitam Nutr Res 1998;68:159-73.

35. Davis BC, Kris-Etherton PM. Achieving optimal essential fatty acid status in vegetarians: current knowledge and practical implications. Am J Clin Nutr 2003;78:640s-6.

36. Willett WC, Howe GR, Kushi LH. Adjustment for total energy intake in epidemiologic studies. Am J Clin Nutr 1997;65:1220S-8. discussion 29S-31S.

37. Burgaz A, Akesson A, Oster A, et al. Associations of diet, supplement use, and ultraviolet $B$ radiation exposure with vitamin $D$ status in swedish women during winter. Am J Clin Nutr 2007;86:1399-404.

38. Wallin A, Di Giuseppe D, Burgaz A, et al. Validity of food frequency questionnaire-based estimates of long-term long-chain n-3 polyunsaturated fatty acid intake. Eur J Nutr 2014;53:549-55.

39. Wolk $A$, Ljung $H$, Vessby $B$, et al. Effect of additional questions about fat on the validity of fat estimates from a food frequency questionnaire. Study Group of MRS SWEA. Eur J Clin Nutr 1998;52:186-92.

40. Larsson SC, Giovannucci E, Wolk A. Dietary folate intake and incidence of ovarian Cancer: the Swedish mammography cohort. $J$ Natl Cancer Inst 2004;96:396-402.

41. Källberg H, Ding B, Padyukov L, et al. Smoking is a Major preventable risk factor for rheumatoid arthritis: estimations of risks after various exposures to cigarette smoke. Ann Rheum Dis 2011;70:508-11.
42. van Gestel AM, Prevoo ML, van 't Hof MA, et al. Development and validation of the European League against Rheumatism response criteria for rheumatoid arthritis. comparison with the preliminary American College of Rheumatology and the World Health Organization/International League against Rheumatism Criteria. Arthritis Rheum 1996;39:34-40.

43. van Gestel AM, Anderson JJ, van Riel PL, et al. ACR and EULAR improvement criteria have comparable validity in rheumatoid arthritis trials. American College of Rheumatology European League of associations for Rheumatology. J Rheumatol 1999;26:705-11.

44. Verhoeven AC, Boers M, van Der Linden S. Responsiveness of the core set, response criteria, and utilities in early rheumatoid arthritis. Ann Rheum Dis 2000;59:966-74.

45. Tetens I, Pedersen AG, Schwab U, et al; Nordic Nutrition Recommendations 2012. 5th edition, 2014:002.

46. Baker JF, Baker DG, Toedter G, et al. Associations between vitamin $\mathrm{D}$, disease activity, and clinical response to therapy in rheumatoid arthritis. Clin Exp Rheumatol 2012;30:658-64.

47. Reboul E. Intestinal absorption of vitamin D: from the meal to the enterocyte. Food Funct 2015;6:356-62.

48. Cutolo M, Pizzorni C, Sulli A. Vitamin D endocrine system involvement in autoimmune rheumatic diseases. Autoimmun Rev 2011;11:84-7.

49. Calder PC. n-3 polyunsaturated fatty acids, inflammation, and inflammatory diseases. Am J Clin Nutr 2006;83:1505S--19.

50. Stamp LK, James MJ, Cleland LG. Diet and rheumatoid arthritis: a review of the literature. Semin Arthritis Rheum 2005;35:77-94.

51. Mohammad BI, Hadi NR, Thwainee AS. The effect of Omega-3 and selenium on Methotrexate-Induced hepatotoxicity. Drug Metabolism Reviews 2010;42:251-51.

52. Proudman SM, Cleland LG, Metcalf RG, et al. Plasma n-3 fatty acids and clinical outcomes in recent-onset rheumatoid arthritis. $\mathrm{Br} J$ Nutr 2015;114:885-90.

53. Jacques PF, Selhub J, Bostom AG, et al. The effect of folic acid fortification on plasma folate and total homocysteine concentrations. N Engl J Med 1999;340:1449-54.

54. Kim YI. Folic acid supplementation and Cancer risk: point. Cancer Epidemiol Biomarkers Prev 2008;17:2220-5.

55. Arabelovic S, Sam G, Dallal GE, et al. Preliminary evidence shows that folic acid fortification of the food supply is associated with higher methotrexate dosing in patients with rheumatoid arthritis. $J$ Am Coll Nutr 2007;26:453-5.

56. Kostoglou-Athanassiou I, Athanassiou P, Lyraki A, et al. Vitamin D and rheumatoid arthritis. Ther Adv Endocrinol Metab 2012;3:181-7.

57. Racovan M, Walitt B, Collins CE, et al. Calcium and vitamin D supplementation and incident rheumatoid arthritis: the Women's Health Initiative Calcium plus Vitamin D trial. Rheumatol Int 2012;32:3823-30. 